\title{
NOTAS SOBRE OS ANTECEDENTES DA GESTÃO METROPOLITANA NA RM DO VALE DO RIO CUIABÁ
}

- processo de contratação, elaboração e implementação dos PDUls, contemplando as soluções de governança do plano, a definição dos instrumentos, os arranjos de gestão e a solução de conflitos de uso e ocupação do solo

Relatório de Pesquisa

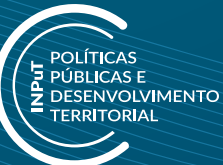





\section{Projeto Governança Metropolitana no Brasil}

\section{NOTAS SOBRE OS ANTECEDENTES DA GESTÃO METROPOLITANA NA RM DO VALE DO RIO CUIABÁ}

- processo de contratação, elaboração e implementação dos PDUls, contemplando as soluções de governança do plano, a definição dos instrumentos, os arranjos de gestão e a solução de conflitos de uso e ocupação do solo

Relatório de Pesquisa 


\section{Governo Federal}

Ministério da Economia

Ministro Paulo Guedes

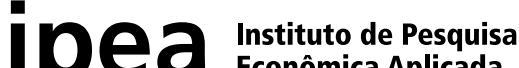 Econômica Aplicada}

Fundação pública vinculada ao Ministério da Economia, o Ipea fornece suporte técnico e institucional às ações governamentais - possibilitando a formulação de inúmeras políticas públicas e programas de desenvolvimento brasileiros - e disponibiliza, para a sociedade, pesquisas e estudos realizados por seus técnicos.

\section{Presidente}

Carlos von Doellinger

Diretor de Desenvolvimento Institucional

Manoel Rodrigues Junior

Diretora de Estudos e Políticas do Estado,

das Instituições e da Democracia

Flávia de Holanda Schmidt

Diretor de Estudos e Políticas

Macroeconômicas

José Ronaldo de Castro Souza Júnior

Diretor de Estudos e Políticas Regionais,

Urbanas e Ambientais

Nilo Luiz Saccaro Júnior

Diretor de Estudos e Políticas Setoriais de Inovação

e Infraestrutura

André Tortato Rauen

Diretora de Estudos e Políticas Sociais

Lenita Maria Turchi

Diretor de Estudos e Relações Econômicas

e Políticas Internacionais

Ivan Tiago Machado Oliveira

Assessor-chefe de Imprensa

e Comunicação (substituto)

João Cláudio Garcia Rodrigues Lima

Ouvidoria: http://www.ipea.gov.br/ouvidoria

URL: http://www.ipea.gov.brURL: http://www.ipea.gov.br 


\section{Projeto Governança Metropolitana no Brasil}

\section{NOTAS SOBRE OS ANTECEDENTES DA GESTÃO METROPOLITANA NA RM DO VALE DO RIO CUIABÁ}

- processo de contratação, elaboração e implementação dos PDUls, contemplando as soluções de governança do plano, a definição dos instrumentos, os arranjos de gestão e a solução de conflitos de uso e ocupação do solo

Relatório de Pesquisa
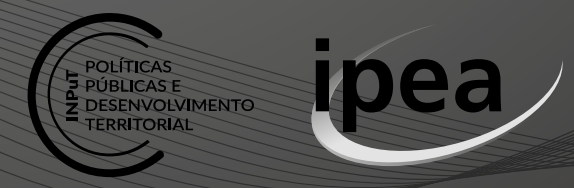

Brasilia, 2021 


\section{COORDENAÇÃO NACIONAL}

\section{Marco Aurélio Costa}

Coordenador nacional do Instituto Nacional de Ciência e Tecnologia (INCT) em Políticas Públicas e Desenvolvimento Territorial (INPuT).

Coordenador da Coordenação de Estudos em Desenvolvimento Urbano (Codur) da Diretoria de Estudos e Políticas Regionais, Urbanas e Ambientais

(Dirur) do Ipea. E-mail: <marco.costa@ipea.gov.br>.

\section{COORDENAÇÃO DO PROJETO GOVERNANÇA METROPOLITANA NO BRASIL}

\section{Marco Aurélio Costa}

Coordenador nacional do INCT/INPuT. Coordenador da Codur/Dirur/Ipea.E-mail: <marco.costa@ipea.gov.br>.

\section{Bárbara Oliveira Marguti}

Pesquisadora na Dirur/lpea. E-mail: <barbara.marguti@ipea.gov.br>.

\section{SUPERVISÃO TÉCNICA}

\section{Bárbara Oliveira Marguti}

Pesquisadora na Dirur/lpea. E-mail: <barbara.marguti@ipea.gov.br>.

\section{Luis Gustavo Vieira Martins}

Pesquisador na Dirur/Ipea. E-mail: <gustavo.martins@ipea.gov.br>.

\section{Lizandro Lui}

Pesquisador do Subprograma de Pesquisa para o Desenvolvimento Nacional (PNPD) na Dirur/lpea. E-mail: <lizandro.lui@ipea.gov.br>.

\section{Sara Rebello Tavares}

Assistente de pesquisa III do projeto Governança Metropolitana no Brasil do Ipea.E-mail: <sara.tavares@ipea.gov.br>.

\section{REVISÃO TÉCNICA}

\section{Bárbara Oliveira Marguti}

Pesquisadora na Dirur/lpea. E-mail: <barbara.marguti@ipea.gov.br>.

\section{Sara Rebello Tavares}

Assistente de pesquisa III do projeto Governança Metropolitana no Brasil do Ipea. E-mail: <sara.tavares@ipea.gov.br>.

\section{AUTORIA}

\section{Alberto Costa Lopes}

Assessor técnico da área de desenvolvimento urbano e meio ambiente do Instituto Brasileiro de Administração Municipal (Ibam). E-mail: <alberto. lopes@ibam.org.br>.

DOI: https://dx.doi.org/10.38116/rp-rmvaledoriocuiaba-notas-comp-b

As publicações do Ipea estão disponíveis para download gratuito nos formatos PDF (todas) e EPUB (livros e periódicos). Acesse: http://www.ipea.gov.br/portal/publicacoes

As opiniões emitidas nesta publicação são de exclusiva e inteira responsabilidade dos autores, não exprimindo, necessariamente, o ponto de vista do Instituto de Pesquisa Econômica Aplicada ou do Ministério da Economia.

É permitida a reprodução deste texto e dos dados nele contidos, desde que citada a fonte. Reproduções para fins comerciais são proibidas. 


\section{SUMÁRIO}

1 INTRODUÇÃO

2 ELABORAÇÃO E APROVAÇÃO DO PLANO METROPOLITANO: ASPECTOS PRINCIPAIS ......................................................

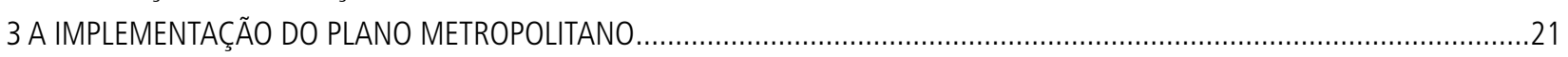

4 CONSIDERAÇÕES FINAIS

REFEREANCIAS

ANEXO A 



\section{INTRODUÇÃO}

A Região Metropolitana (RM) do Vale do Rio Cuiabá, no estado de Mato Grosso, Centro-Oeste do Brasil, encontra-se instituída como figura de planejamento e gestáo governamental pela Lei Complementar Estadual (LCE) no 359, de 27 de maio de 2009. Essa LCE, por sua vez, teve como base outro ato legal anterior, a LCE no 340, de 17 de dezembro de 2008, que havia estabelecido regras e princípios gerais atualizados sobre o assunto no estado.

O processo legislativo e institucional sobre o assunto é relativamente recente, tendo iniciado com a criação, em 1993, da figura do aglomerado urbano, originalmente formado apenas por Cuiabá e Várzea Grande. Vale lembrar que o marco legal e as primeiras iniciativas oficiais de planejamento e gestáo metropolitana no Brasil datam da virada da década de 1960 para a de 1970, quando foram instituídas as nove primeiras RMs no Brasil.

A RM do Vale do Rio Cuiabá, longe das áreas de ocupação mais antigas e dinâmicas da urbanização brasileira, acabaria experimentando um processo geográfico mais retardatário de metropolização.

$\mathrm{Na}$ fase mais recente, a transformação dessa região de aglomerado urbano para RM foi acompanhada pela incorporação de mais dois municípios (Nossa Senhora do Livramento e Santo Antônio de Leverger), por força da LCE no 359/2009. Posteriormente, a LCE no 577/2016 promoveu outros dois municípios (Acorizal e Chapada dos Guimaráes) da condição de pertencentes ao entorno metropolitano a integrantes da RM. Atualmente, a RM do Vale do Rio Cuiabá é integrada por seis municípios, enquanto outros sete compóem o chamado entorno metropolitano. Aqueles seis municípios somam hoje uma população que poderá atingir, talvez já no Censo Demográfico de 2020, 1 milhão de habitantes, maioritariamente concentrados nas cidades de Cuiabá e Várzea Grande. De todo modo, todos os seis municípios possuem grandes extensôes territoriais, o que sugere que os espaços não urbanos tendem a exigir políticas integradas com os espaços urbanos.

A evolução dessa formação territorial e institucional gerou arranjos institucionais que sofreram algumas alteraçôes em função dos contextos geográfico e político-institucional da época. A fase pioneira do planejamento e da gestão metropolitana na região, desde a criação do aglomerado urbano de Cuiabá e Várzea Grande, no entanto, não chegou a consolidar um ambiente institucional de mínima continuidade de políticas e ações, nem foi capaz de resistir às transiçóes dos mandatos político-administrativos de governo. Não chegou a se formar na região um imaginário pedagógico sobre a natureza e o desafio da questão metropolitana e da agenda pública dela derivada. Tampouco se logrou experimentar práticas cooperativas sistemáticas de governo, sejam horizontais, entre os municípios, sejam interfederativas, entre os municípios e o estado.

Apesar disso, vale observar que, do ponto de vista estritamente formal da estrutura legal e do respectivo desenho institucional da gestão metropolitana na região, o advento da lei federal que instituiu o Estatuto da Metrópole, em janeiro de 2015, encontrou no marco legal estadual então vigente algumas referências que puderam ser aproveitadas e aperfeiçoadas nos anos seguintes.

Cabe observar que, ao contrário da maioria das RMs do Brasil que vieram sendo nomeadas pela sua cidade mais dinâmica ou importante, muitas das vezes uma capital de estado, como Cuiabá, observa-se que a RM do Vale do Rio Cuiabá foi nomeada pela figura geográfica e estruturante do vale do rio que abriga todos os municípios que a compóem. 
Esse critério de nomeação das RMs no Brasil, defendido em trabalho publicado por este autor na literatura especializada sobre o assunto, tem um significado simbólico no sentido de não refletir uma suposta subordinação do conjunto dos municípios à cidade central. Ao contrário, busca-se superar a noção de centro e periferia. No cenário institucional de cooperação em equilíbrio federativo e de representação de todos os municípios junto ao estado enunciado no Estatuto da Metrópole, esse critério de nomeaçáo das RMs tende a se mostrar mais motivador para os municípios de menor ascendência nas decisóes colegiadas do ambiente de gestáo.

Outra observaçáo importante é que o Plano de Desenvolvimento Urbano Integrado (PDUI), tal como nomeado na Lei Federal no 13.089/2015 (Estatuto da Metrópole), foi identificado e aprovado na legislação do estado de Mato Grosso como Plano Diretor de Desenvolvimento Integrado (PDDI), pautando-se igualmente por aquele marco legal federal. De todo modo, no nosso entendimento, essa diferença sutil observada na definiçáo do nome do plano dessa RM do vale mato-grossense em relação ao nome definido no Estatuto da Metrópole acabou por enfatizar o conceito de desenvolvimento indiferenciado em todo o território urbano e não urbano implicado nos seis municípios. Afinal, na esfera local, os planos diretores municipais também estáo obrigados a cobrir todo o território dos municípios.

Um quadro resumo da evolução da legislação estadual no assunto é apresentado no anexo A.

\section{ELABORAÇÃO E APROVAÇÃO DO PLANO METROPOLITANO: ASPECTOS PRINCIPAIS}

\subsection{0 processo de elaboração do plano metropolitano}

Segundo apurado localmente, a elaboração do PDDI da RM do Vale do Rio Cuiabá, vigente desde dezembro de 2018, foi de iniciativa da atuante Procuradoria de Urbanismo e Meio Ambiente do Ministério Público do Estado de Mato Grosso (MPMT). Em 2012, antes, portanto, do advento do Estatuto da Metrópole, uma iniciativa do governo do estado de elaboração de um plano metropolitano para a região, contratado a uma empresa privada, havia sido interrompida, gerando estudos, mas sem chegar a gerar as propostas esperadas para constituir um ato legal.

Aprovado o Estatuto da Metrópole, em janeiro de 2015, sem que a nova administração do governo do estado reagisse para o cumprimento do prazo legal para elaborar o plano metropolitano, pelo menos enquanto o MPMT avaliou como razoável para o esperado da administração pública, a procuradoria cuidou de pautar o assunto junto ao Executivo estadual. Vale registrar, desde já, que essa procuradoria acabou por acompanhar vivamente todo o processo do plano, tanto junto ao órgão metropolitano então responsável (a Agência de Desenvolvimento Metropolitano - Agem da RM do Vale do Rio Cuiabá), quanto nas diversas reunióes e audiências públicas realizadas, enviando pessoal qualificado para esses eventos públicos na capital e nos demais municípios da região.

O processo de contratação foi realizado por meio de licitação do tipo técnica e preço. Elaboradas as peças necessárias ao lançamento da concorrência pública (edital e seu respectivo termo de referência), a publicação desse ato administrativo ocorreu em 26 de abril de 2016, assim registrado oficialmente: 
- Edital de Concorrência Pública no 001/2016/Agem/VRC;

- Processo no 015/2015/Agem/VRC; e

- Data da abertura e julgamento das propostas: 24 de junho de 2016.

O Ibam, como único a se apresentar na concorrência e tendo cumprido todas as exigências do edital e do termo de referência, foi o vencedor do certame, iniciando os trabalhos no fim do mês de julho de 2016. O ciclo desse trabalho de consultoria, previsto em contrato para ser executado em onze meses, finalizou em julho de 2018, totalizando cerca de 24 meses, apoiado em aditivos justificados pelas exigências do tempo local e pela decisão de consolidar o processo e os resultados do trabalho num livro não previsto no contrato original.

De fato, o tempo de consultoria não costuma corresponder ao tempo local. A experiência mostra que há sempre uma estimativa de tempo para a execução desse tipo de trabalho contratado que náo corresponde à capacidade de respostas locais às diversas demandas dos trabalhos. O tempo necessário ao processo participativo, particularmente, mas não só este, tende a exigir a extensão dos prazos contratuais. No mesmo sentido, a previsão de prazos curtos pelos contratantes busca justificar orçamentos menores frente às conhecidas dificuldades financeiras do setor público no Brasil. A nosso ver, de fato, o que ocorre é uma confusão entre tempo de orçamento, avaliado como se o curso do trabalho pudesse seguir compacto e sem interrupçóes, e tempo de execução, alargado em função de exigências locais.

O último ato público de encerramento do trabalho foi realizado em 5 de julho de 2018, no Palácio Payaguás, sede do governo estadual, com o lançamento do livro do Plano Diretor de Desenvolvimento Integrado da Regiāo Metropolitana do Vale do Rio Cuiabá. A lei que instituiu o PDDI da RM do Vale do Rio Cuiabá foi aprovada e publicada no Diário Oficial do estado de Mato Grosso no dia 27 de dezembro de 2018.

\subsubsection{Escopo geral do trabalho}

O objeto e a justificativa da elaboração do plano metropolitano foram assim definidos no termo de referência: elaboraçáo do PDDI da RM do Vale do Rio Cuiabá, contendo diretrizes para o seu planejamento de curto, médio e longo prazos - dez anos (art. 11 do Estatuto da Metrópole): "definindo o conjunto de grandes linhas de ações voltadas à promoção do desenvolvimento sustentável da RMVRC, visando à unidade territorial, à redução de desigualdades entre os municípios" (Brasil, 2015). Para efeito de elaboração do plano metropolitano, as funçóes públicas de interesse comum (FPICs) foram assim definidas no item 8 do termo de referência, referindo-se às disposiçóes da LCE no 359/2009:

- desenvolvimento econômico e social;

- planejamento do uso e ocupação do solo;

- acessibilidade e mobilidade;

- preservação e conservação do meio ambiente;

- saneamento ambiental; e

- desenvolvimento urbano e políticas setoriais.

As FPICs, por sua vez, foram traduzidas nos seguintes eixos aglutinadores (ou estruturadores):

- eixo I - economia regional, desenvolvimento econômico, social, desenvolvimento urbano e políticas setoriais (habitação, saúde, educação, segurança, lazer, turismo, esporte; 
- eixo II - planejamento do uso e ocupação do solo, acessibilidade, mobilidade urbana, transporte e logística; e

- $\quad$ eixo III - planejamento e meio ambiente, preservação e conservação do meio ambiente, saneamento ambiental e resíduos sólidos.

\subsubsection{Requisitos metodológicos}

1) Compatibilização entre planos, projetos e legislaçôes relacionadas aos temas nas esferas municipais, estadual e federal.

2) Utilização de dados secundários, estudos, levantamentos e planos oficiais e/ou de reconhecida confiabilidade.

3) Coleta de informaçôes em visitas técnicas aos municípios e órgãos do governo estadual e federal, relacionados ao planejamento e à execução das FPICs.

4) Utilização de metodologias consagradas para realização de cenários e projeções relacionadas aos temas de interesse comum.

5) Proposição de planos, programas e açóes para curto, médio e longo prazo (dez anos - art. 11 do Estatuto da Metrópole).

6) Abordagem (democrática e inclusiva) específica para os processos participativos e de apoio à gestão pública visando obter melhores resultados no envolvimento dos atores do processo, quais sejam: gestores públicos, sociedade civil organizada, Ministério Público e população geral.

7) Reuniōes com órgãos do governo estadual, legislativos e representantes das administraçôes municipais mais gestores públicos, sociedade civil organizada, Ministério Público e população em geral.

8) Georreferenciamento de dados, diagnósticos e prognósticos.

Compatibilizaçóes do PDDI com (pelo menos):

- planos diretores municipais;

- planos setoriais municipais;

- planos, programas e ações do governo federal em execução na RMdo Vale do Rio Cuiabá;

- projetos estruturadores do governo do estado, com açóes no âmbito da RM do Vale do Rio Cuiabá;

- Plano Plurianual de Ação Governamental (PPAG);

- legislações em vigor, relativas ao arranjo institucional da RM do Vale do Rio Cuiabá, bem como outras legislaçôes relacionadas à região;

- açóes, planos, projetos e investimentos públicos e/ou privados em curso e/ou previstos para a RM do Vale do Rio Cuiabá.

Indicações metodológicas para a etapa 1 da proposta técnica do Ibam:

- exercício exploratório de relaçóes matriciais entre as FPICs com base nos eixos estruturadores;

- entrevistas estruturadas com atores-chave;

- observação participante;

- grupos focais;

- técnica de visualização por cartôes (Metaplan); 
- Matriz Swat/Fofa;

- exercício de diagnóstico rápido e participativo.

\subsubsection{Referências em etapas metodológicas}

1) Etapa 0 - preparação (conforme a proposta técnica apresentada pelo Ibam):

a) mapear os principais interlocutores envolvidos na realização das atividades, bem como os pontos focais nos seis municípios da RM;

b) pré-identificar tendências de ocupação do território, por meio de percorridos e visitas, utilizando o instrumental metodológico de técnicas de leitura do espaço urbano e identificaçáo de signos especiais e observação participante;

c) identificar e coletar material institucional (planos, projetos, orçamentos públicos, plano plurianual - PPAs etc.); e

d) instalar a equipe local da consultoria, bem como negociar com a Agem da RM do Vale do Rio Cuiabá os processos e graus de colaboraçáo para o desenvolvimento do trabalho.

Para a organização e realização dos eventos, foi acertado entre a Agem da RM do Vale do Rio Cuiabá e o Ibama divisão e o compartilhamento de atribuições e responsabilidades técnicas e logísticas entre as partes.

2) Produto 0 - plano de trabalho: cronograma com datas reais, metodologia descrita e detalhada, plano de participaçáo social, plano de comunicação, incluindo página na internet, conta no Facebook e endereço eletrônico para comunicação direta entre a equipe executora do trabalho pelo Ibam e os interessados em geral. Na página da internet, foram disponibilizados para consulta, com a antecedência mínima de quinze dias, todos os documentos produzidos no processo de trabalho, que foram objeto das audiências públicas realizadas. ${ }^{1}$

3) Etapa 1 - diagnóstico: por FPIC

Desenvolvimento econômico e social

a) dinâmica demográfica: principais dados e tendências;

b) avaliação da evolução, tendências e componentes do produto interno bruto (PIB), dos empregos formais, renda, dos setores econômicos que apresentam maior dinamismo e suas relaçóes espaciais de complementaridade, economias de aglomeração, gargalos);

c) identificaçáa dos principais investimentos públicos e privados implantados e/ou em vias de implantaçáo na regiáo, ou que afetam direta ou indiretamente a RM do Vale do Rio Cuiabá;

d) identificação da vocação econômica e da complementaridade de (e entre) cada um dos municípios que compóem a RM do Vale do Rio Cuiabá;

e) identificação de áreas e grupos em situação de vulnerabilidade social;

f) identificação dos indutores do desenvolvimento, da geração de emprego e renda e inclusão social; e

g) outros elementos relevantes identificados no decorrer dos trabalhos. 
Planejamento do uso e ocupação do solo

a) levantamento e análise das ocupações em área de risco iminente;

b) identificação da distribuição espacial da população (densidade, perfil socioeconômico);

c) levantamento de áreas de produção agrícola e principais tipos de cultura analisadas segundo potenciais conflitos entre a expansão urbana e o meio rural;

d) identificação das áreas de relevância ambiental para preservação, conservação, regeneração ou de riscos iminentes;

e) levantamento e análise da evolução urbana e tendências de expansão na RM, considerando os elementos estruturadores do território e suas conurbaçóes;

f) legislações pertinentes ao ordenamento territorial dos municípios com a identificação dos conflitos e complementaridades: $i$ ) planos diretores; $i$ ) leis de zoneamento, uso e ocupação do solo; iii) leis de hierarquização viária; iv) planos de habitação; v) planos de saneamento ambiental; e vi) planos de acessibilidade e mobilidade;

g) legislaçóes estaduais pertinentes ao tema; $\mathrm{e}$

h) outros elementos relevantes identificados no decorrer dos trabalhos.

Acessibilidade e mobilidade urbana

a) levantamento e análise dos planos de mobilidade dos municípios da RM do Vale do Rio Cuiabá, de movimentos pendulares e dos principais deslocamentos metropolitanos;

b) levantamento e análise dos modais de transportes de locomoção, motorizados e não motorizados existentes, em implantação e de demandas futuras;

c) identificação dos polos geradores de tráfego, seu potencial em comprometer a segurança e o desempenho do sistema viário, bem como a localização dos eixos viários passíveis de sobrecarga;

d) levantamento do sistema macroviário (eixos estratégicos consolidados ou potenciais) e sua hierarquização viária (baseada na geometria e relevância);

e) outros elementos relevantes identificados no decorrer dos trabalhos.

Preservação e conservação do meio ambiente

a) identificaçáo, qualificação e mapeamento das nascentes e afluentes do rio Cuiabá, bem como dos impactos negativos que esses vêm sofrendo;

b) identificação e análise de áreas restritas para ocupação vinculadas a questôes ambientais e ao patrimônio cultural (utilizando-se inclusive de fontes secundárias) incluindo: $i$ ) legislações de proteção ao patrimônio e à paisagem; $i$ ) estudos disponíveis referentes às questôes ambientais da RM do Vale do Rio Cuiabá; iii) tombamentos de áreas de interesse ambiental, paisagístico, arquitetônico e cultural no âmbito federal, estadual e municipal; iv) áreas de preservação prioritárias e protegidas e unidades de conservação; $v$ ) áreas com riscos ambientais; vi) exploração de recursos naturais; vii) áreas contaminadas; viii) incidência de medidas de proteção do patrimônio e seu entorno; e $i x$ ) outros elementos relevantes identificados no decorrer dos trabalhos.

Saneamento ambiental

a) levantamento de projetos estratégicos e previsão de investimentos para o setor em todas as instâncias governamentais; 
b) levantamento e análise de planos municipais e estaduais de saneamento básico (resíduos sólidos, drenagem, água e esgotamento sanitário);

c) levantamento qualitativo e quantitativo das macroestruturas de saneamento (resíduos sólidos, drenagem, água e esgotamento sanitário);

d) identificação das atividades de exploração de recursos naturais e análise de seus potenciais impactos;

e) identificação de áreas degradadas em especial áreas de mananciais;

f) outros elementos relevantes identificados no decorrer dos trabalhos.

Desenvolvimento urbano e políticas setoriais

a) habitação: situação habitacional, abordando os déficits, as demandas e inadequaçôes etc.; projetos habitacionais implantados e em implantação pela iniciativa privada e por programas de governo; e outros elementos relevantes identificados no decorrer dos trabalhos;

b) saúde, educação, segurança e lazer: avaliação quantitativa e qualitativa da oferta e demanda por atendimento nos diversos serviços, bem como o inter-relacionamento e interdependência entre os municípios; e outros elementos relevantes identificados no decorrer dos trabalhos;

c) turismo: identificação dos tipos de turismo praticados; identificação dos principais polos turísticos existentes, e dos potenciais exploráveis; levantamento e análise qualitativa e quantitativa da infraestrutura turística; obstáculos ao desenvolvimento do setor; e outros elementos relevantes identificados no decorrer dos trabalhos; e

d) esporte: levantamento e análise qualitativa e quantitativa da infraestrutura esportiva; identificação de vocação esportiva e de potencialidades; levantamento e análise de obstáculos ao desenvolvimento profissional do setor conforme modalidades em evidência; e outros elementos relevantes identificados no decorrer dos trabalhos.

Produto $1 \mathrm{a}$ - relatório das reuniôes estruturadas/audiências públicas municipais.

Produto $1 \mathrm{~b}$ - relatório 1/diagnóstico consolidado.

4) Etapa 2 - prognóstico

a) Projeçôes e cenários 2016-2026 considerando (item 10.2 do TR):

- evolução populacional;

- ocupação territorial;

- economia/conjuntura econômica nacional.

Produto $2 \mathrm{a}$ - relatório da audiência pública final.

Produto $2 \mathrm{~b}$ - relatório 2/cenários e proposiçōes.

5) Etapa 3 - PDDI

Elementos estruturadores do PDDI

Os elementos estruturadores instruem também a estrutura do Projeto de Lei (PL) do PDDI:

a) diretrizes para as FPICs por meio de planos, programas, projetos estratégicos e a hierarquização de açôes prioritárias para investimentos; 
b) diretrizes para a integração do transporte intermunicipal no âmbito da RM do Vale do Rio Cuiabá;

c) proposição de zoneamento integrado compondo o macrozoneamento da RM do Vale do Rio Cuiabá;

d) delimitação das áreas com restrição a urbanização visando à proteção do patrimônio ambiental e/ou cultural, bem como das áreas sujeitas ao controle especial pelo risco de desastres naturais;

e) diretrizes quanto à articulação dos municípios no parcelamento, no uso e na ocupação do solo urbano;

f) proposições de ações de governança interfederativa para a implantação do plano;

g) diretrizes para a articulação intersetorial das políticas afetadas na unidade territorial da RM do Vale do Rio Cuiabá; e

h) elaboração de mapas síntese das estratégias adotadas.

Produto 3a - volume I: diagnóstico (preliminar)

Volume II: prognóstico (preliminar);

Volume III: dossiê geral (preliminar).

Produto 3b - volume IV: texto legal do PDDI comentado (preliminar)

Elementos estruturadores do PDDI

Produto 4a - volume I: diagnóstico (final)

Volume II: prognóstico (final);

Volume III: dossiê geral (final).

Produto $4 \mathrm{~b}$ - volume IV: texto legal do PDDI comentado (final)

Elementos estruturadores do PDDI;

Etapa 4 - encerramento da elaboração do PDDI.

Produto $5 \mathrm{a}$ - evento para lançamento do PDDI (com o aditivo de contrato, este evento acabou sendo feito com o próprio lançamento do livro do PDDI).

Produto $5 \mathrm{~b}$ - reuniôes de capacitação dos técnicos da Agem.

Produto 5c - relatório consolidado dos eventos de divulgação e capacitação.

\subsubsection{A aprovação do plano metropolitano}

O processo de construção da minuta do texto legal que resultou na Lei Complementar no 609/2018, que instituiu o PDDI da RM do Vale do Rio Cuiabá, pode ter contribuído para a sua tramitação relativamente bem-sucedida na Assembleia Legislativa do Estado de Mato Grosso (ALMT). Da redação da primeira minuta do anteprojeto de lei até a redação final do PL efetivamente enviado pelo Executivo estadual para tramitação na ALMT, se sucederam uma audiência pública e várias rodadas de reunióes realizadas com a participação ativa de 
técnicos e representantes das procuradorias jurídicas das seis prefeituras e do estado, da Agem da RM do Vale do Rio Cuiabá e do MPMT, além da coordenação técnica e da consultoria jurídica do Ibam. Finalmente, antes do PL ser enviado à tramitação na ALMT, o anteprojeto de lei, já submetido ao debate e às contribuiçóes nas rodadas anteriores de discussão, inclusive públicas, foi aprovado pelo Conselho Deliberativo Metropolitano (Codem) do Vale do Rio Cuiabá.

$\mathrm{Na}$ entrada do Projeto de Lei Complementar (PLC) enviado pelo Executivo estadual à ALMT o assunto ganhou as seguintes referências para a sua tramitação e o seu acompanhamento: PLC no 7/2018; Mensagem no 49/2018; Protocolo no 3287/2018; e Processo no ${ }^{8} 22 / 2018$. A direção da Agem do Vale do Rio Cuiabá e outros membros da equipe técnica e política do governo estadual, incluindo a Procuradoria-Geral do Estado (PGE) e a assessoria legislativa, conduziram todo o processo de envio e de tramitação do PL junto à ALMT.

Foram incluídas e aprovadas apenas duas emendas ao PL original: uma relativa à redação que se referia à autonomia municipal frente à gestáo das chamadas FPICs e outra relativa a contratos de concessão então vigentes e expedidos pelo estado para transporte intermunicipal com bilhetagem eletrônica. Acolhidas essas duas emendas, o PL foi aprovado em primeira votação em 28 de novembro de 2018 e depois na segunda e última votação com o texto final publicado no Diário Oficial do Estado de Mato Grosso de 27 de dezembro de 2018.

O ponto central de discussão, que resultou na primeira emenda, desde a primeira versão da minuta apresentada pelo Ibam até a votação do PL, foi a fronteira de interpretação entre a autonomia municipal e as FPICs. Vale ressaltar que esse debate foi lançado e sustentado pela Prefeitura de Várzea Grande, mantendo atitude afirmativa no jogo de forças que a nova institucionalidade do PDDI anunciava e evitando se subordinar à força do Estado e do município da capital. O silêncio dos quatro municípios de menor ascendência na regiáo nessa questão, no nosso juízo, explicava-se pelo fato de só terem a ganhar ao serem incluídos na região e nos espaços de gestáo interfederativos.

$\mathrm{Na}$ verdade, como sustentou a coordenação do Ibam desde o início dos debates, até mesmo pela origem e missão municipalista do instituto, a autonomia municipal estava garantida na Constituição Federal, associada inclusive a competências exclusivas dos municípios, podendo ser facilmente defendida em algum contencioso que viesse a surgir. A articulação interfederativa em torno das FPICs, por sua vez, num ambiente de construção de uma nova cultura de cooperação interfederativa no país e na regiáo, precisava ser vista mais como oportunidade do que como ameaça. Essa foi a tese e a pedagogia sustentada pela coordenação do Ibam no assunto. Por sua vez, o desenho institucional do ambiente de gestão metropolitana proposto na lei complementar, tal como preconizado pelo Estatuto da Metrópole, garantia paridade nas manifestaçóes e decisóes que viessem a ser tomadas.

O Estatuto da Metrópole, inciso II do seu art. 2º, definiu FPIC como "política pública ou ação nela contida cuja realização por parte de um município, isoladamente, seja inviável ou cause impacto em municípios limítrofes" (Brasil, 2015). O que o Estatuto da Metrópole náo acrescentou a essa definiçáo é a visão positiva e agregadora que as oportunidades de ação conjunta entre os municípios também podem constituir na mobilização de iniciativas, desejos e vontades baseadas em resultados a serem compartilhados. Nessa perspectiva, a escala da ação de cada município envolvido na resolução das FPICs continua sendo a sua própria jurisdição territorial, mas, contra a concorrência, a omissão ou o imobilismo predador de algum eventual ente federativo, assume-se a escala regional ou sub-regional como a única escala em que, frente ao desafio das FPICs, todos os municípios podem ganhar. Se isso já era 
uma tese nas iniciativas de articulação via os velhos consórcios horizontais entre municípios, mais ainda no âmbito das possibilidades abertas pelos consórcios públicos (verticais) com a possibilidade de participaçáo do estado e da Uniáo ou ainda pela gestáo interfederativa preconizada no Estatuto da Metrópole.

\subsection{Caracterização geral do plano metropolitano aprovado}

\subsubsection{A estrutura geral do plano metropolitano}

O PDDI da RM do Vale do Rio Cuiabá, aprovado pela LCE no 609/2018 está estruturado em cinco capítulos, conforme segue.

Capítulo I - Disposições Gerais

Seção I - Disposições Preliminares

Seção II - Das Estratégias

Capítulo II - Da Governança Interfederativa

Seção I - Dos Princípios de Governança

Seção II - Da Estrutura de Governança

Seção III - Da Gestão Metropolitana

Capítulo III - Dos Programas Metropolitanos (cada programa estruturado em componentes e açóes)

Seção I - Do Programa Gestão Metropolitana

Seção II - Do Programa Cidadania para o Desenvolvimento

Seção III - Do Programa Identidade Cultural Regional

Seção IV - Do Programa Economia Regional Dinamizadora

Seção V - Do Programa Terra Regular

Seção VI - Do Programa Urbanismo em Rede

Seção VII - Do Programa Mobilidade Metropolitana Integradora

Seção VIII - Do Programa Saneamento Ambiental

Seção IX - Do Programa Vale Sustentável

Capítulo IV - Dos Instrumentos

Seção I - Disposiçôes Gerais

Seção II - Do Macrozoneamento Metropolitano 
Seção III - Dos Planos Diretores Municipais

Seção IV - Do Estudo de Impacto de Vizinhança

Seção V - Da Anuência Prévia Metropolitana

Seção VI - Dos Instrumentos Orçamentários

Seção VII - Dos Planos, Programa e Projetos Metropolitanos Setoriais

Capítulo V - Disposiçôes Finais e Transitórias

Componentes dos programas metropolitanos: capitulo III

Programa Gestão Metropolitana

- organização da administração;

- recursos financeiros;

- gestão da informação;

- mídia metropolitana; e

- monitoramento e avaliação.

Programa Cidadania para o Desenvolvimento

- promoção do acesso aos serviços sociais;

- fomento à participação popular nas decisóes;

- democratização dos espaços públicos; e

- segurança cidadá.

Programa Identidade Cultural Regional

- patrimônio metropolitano;

- cultura cidadá; e

- vale criativo e turístico.

Programa Economia Regional Dinamizadora

- desenvolvimento de cadeias produtivas e redes de serviços;

- alimentando a metrópole; e

- plataforma metropolitana de logística integrada.

Programa Terra Regular

- $\quad$ regularidade de divisas intermunicipais;

- regularidade fundiária urbana;

- regularidade fundiária rural; e

- regularidade nas Unidades de Conservação e outras áreas protegidas. 
Programa Urbanismo em Rede

- instrumentos municipais de planejamento urbano;

- qualidade dos espaços públicos; $\mathrm{e}$

- moradia na RMdo Vale do Rio Cuiabá.

Programa Mobilidade Metropolitana Integradora

- $\quad$ integração da mobilidade na Região Metropolitana do Vale do Rio Cuiabá;

- calçadas plenas.

Programa Saneamento Ambiental

- conservação de recursos hídricos;

- viver sem contaminação; e

- redução e controle de perdas.

Programa Vale Sustentável

- conservação ambiental;

- economia para a sustentabilidade;

- infraestruturas para a sustentabilidade.

Com base no estabelecido no Estatuto da Metrópole, a estrutura e o roteiro temático do PDDI foram construídos a partir dos estudos de diagnóstico e do conhecimento gerado nas reunióes e audiências públicas realizadas. Um documento de cenários e proposiçóes foi construído e submetido a debate público buscando-se uma visão prospectiva de futuro. O cenário de aposta do trabalho foi nomeado como Piracema, referindo-se a um fenômeno natural fortemente identificado com o meio natural da regiáo, denotando superação coletiva das condiçôes então verificadas de desenvolvimento.

O conteúdo central da lei do PDDI contempla basicamente o desenho da governança interfederativa, os programas metropolitanos a serem implementados e os seus instrumentos administrativos de ação. Dado o estado nascente da governança metropolitana na regiáo em busca de desenvolvimento e consolidação, um dos programas metropolitanos foi criado justamente para promover a capacidade de ação do ambiente interfederativo de gestão. Os outros programas, temáticos ou setoriais, respondem diretamente ao conjunto das FPICs e às grandes questóes que emergiram do diagnóstico e dos debates públicos. A construção desses programas, desde os estudos de diagnóstico, partiu também de uma visão matricial e das múltiplas interrelaçóes entre os temas e as funçóes de governo: uso do solo e economia; cidadania e mobilidade; urbanismo e terra; saneamento ambiental e sustentabilidade e assim por diante.

No âmbito de quase todos os programas, havia, em curso ou em formação, algumas iniciativas de governo, do setor privado ou de outros atores que ora se identificavam como parceiros, ora como protagonistas potenciais das açôes a serem levadas adiante na implementaçáo do PDDI. Cada programa metropolitano também foi estruturado em componentes, num total de trinta, afim de permitir ações focadas em resultados mais tangíveis pela administração pública e pelos potenciais beneficiários. 
Vale destacar que o caráter e os nomes atribuídos aos programas metropolitanos buscaram uma fácil identificação de marca para a açâo de governo a ser implementada. $\mathrm{O}$ Programa Urbanismo em Rede talvez seja uma inovação, pois

tem por objetivo instituir mecanismos de gestão integrada e cooperativa entre os entes metropolitanos responsáveis pela gestão das áreas urbanas e de expansão urbana da região. Sem ferir a autonomia dos municípios, mas atentos ao interesse coletivo frente ao interesse individual, isso inclui trabalhar pela definição de estratégias conjuntas na definição dos perímetros urbanos, planos diretores, legislação urbanística geral, padróes de qualidade para os espaços públicos e moradia (Lopes, 2018).

Esse campo de ação cooperativa horizontal proposto entre os municípios, para além do âmbito estritamente metropolitano, previu inclusive iniciativas não necessariamente definidas como FPICs.

Finalmente, a vigência do PDDI foi definida em dez anos e foi dado prazo para a adoção de algumas medidas e providências posteriores à aprovaçáo da lei no sentido de melhorar as condições para a sua implementação.

\subsubsection{Macrozoneamento metropolitano, conflitos de uso do solo e compatibilização com os planos diretores municipais}

ALC que instituiu o PDDI da RM do Vale do Rio Cuiabá no seu capítulo IV/seção II (Dos instrumentos) trata especificamente do macrozoneamento metropolitano. Cabe registrar que a lei inclui os mapas anexos 1 e 2 que definem em caráter geral a delimitação das distintas zonas. No entanto, como é muito comum no processo legislativo no Brasil, a publicação da lei no Diário Oficial do Estado de Mato Grosso não incluiu essas peças gráficas, em complementação ao texto legal, para o indispensável acesso público.

A esse respeito, cabe ainda esclarecer que, mesmo vencidas algumas insuficiências das bases georreferenciadas da cartografia disponível no processo de trabalho de elaboração do plano, ficou evidenciada a necessidade de um esforço permanente da gestáo metropolitana no âmbito da estrutura interfederativa proposta no PDDI no sentido de estado e municípios criarem mecanismos de aperfeiçoamento e atualização permanente da informação geográfica sobre a região.

O macrozoneamento busca dar suporte e condiçôes territoriais à implementação dos diversos programas do PDDI. O Programa Terra Regular, por exemplo, visa melhorar as condiçóes do chassi territorial da região, no sentido de destravar processos, facilitar o acesso a crédito, agilizar e ampliar a produtividade geral do desenvolvimento regional.

O macrozoneamento é composto por: $i$ ) zonas de estruturação do território metropolitano; ii) eixos estruturais; e iii) áreas de interesse metropolitano.

Quanto à relação do macrozoneamento metropolitano com os planos diretores municipais, o processo de elaboraçáo do PDDI da RM do Vale do Rio Cuiabá encontrou uma situação diversa nos seis municípios da região. Cuiabá, Várzea Grande e Chapada dos Guimarães tinham seus planos diretores aprovados, mas com algum grau de desatualização frente a novos fatos surgidos nos últimos anos. Os outros três municípios, entre os menores da região, não dispunham de planos diretores, senão de algumas leis esparsas e pouco consistentes tratando de questôes específicas como perímetros urbanos, por exemplo. 
No segundo semestre de 2016, no curso da elaboraçáo do PDDI, havia uma iniciativa em construção pela Secretaria de Cidades do Governo do Estado de Mato Grosso no sentido de apoiar a elaboração de alguns planos diretores no estado, inclusive de alguns municípios integrantes da região metropolitana. Até a conclusão do PDDI, essa iniciativa não havia se concretizado. Houve mesmo uma atitude dos municípios e do estado de aguardar a conclusão do plano metropolitano como um marco de referência para a elaboração ou revisão dos planos diretores municipais.

De fato, logo após a aprovação do PDDI, a Prefeitura de Várzea Grande, por meio de processo licitatório, deu início à elaboração/revisão do seu plano. $\mathrm{O}$ município de Nossa Senhora do Livramento também elaborou o seu, com assessoria local. E Cuiabá (fevereiro de 2020) encontra-se em processo licitatório para a atualização do seu plano, tendo incluído no edital e em seu respectivo termo de referência menção à necessidade de os concorrentes situarem a questáo local no âmbito metropolitano. O capítulo IV (Dos instrumentos)/seção III (Dos planos diretores municipais) da lei que instituiu o PDDI dispóe especificamente sobre o assunto.

Sobre possíveis conflitos relacionados à sobreposição de zoneamento metropolitano aos zoneamentos municipais, cabe registrar dois fatores. Primeiro, a existência de planos diretores somente para três dos seis municípios metropolitanos. Segundo, a relativa grande distância entre as sedes urbanas municipais (as cidades) num quadro de zoneamentos quase que exclusivamente definidos para as áreas urbanas. Por seu turno, no caso da fronteira entre Cuiabá e Várzea Grande, trata-se de uma conurbação que tem como limite o rio Cuiabá, sem continuidade concreta das malhas urbanas.

No processo de trabalho, foram verificadas ainda mais oportunidades conjuntas de articular e compatibilizar os zoneamentos municipais com o metropolitano do que conflitos entre eles. De todo modo, essas oportunidades dependem de uma visão metropolitana compartilhada de mais longo prazo no sentido de equilibrar a enorme concentração de oferta de trabalho, comércio, serviços e amenidades urbanas nos dois maiores municípios conurbados da região.

\subsubsection{0 arranjo institucional criado}

A estrutura institucional normativa atual da RM do Vale do Rio Cuiabá, definida no capítulo II - da governança interfederativa da Lei Complementar Estadual no 609/2018, com a alteração advinda da extinção da Agem da RM do Vale do Rio Cuiabá, compreende:

- O Codem da RM do Vale do Rio Cuiabá;

- O Conselho Executivo Metropolitano (Consem) composto pelo governador do estado de Mato Grosso e prefeitos dos municípios integrantes da RM do Vale do Rio Cuiabá;

- A Secretaria Adjunta de Gestão e Planejamento Metropolitano (SAGPM) - sucessora da Agem/RM do Vale do Rio Cuiabá), vinculada à Secretaria Estadual de Infraestrutura e Logística (Sinfra) do Executivo estadual; e

- O Fundo de Desenvolvimento Metropolitano (FDM) da RM do Vale do Rio Cuiabá.

Uma observação importante é que nesse capítulo II da LCE que instituiu o PDDI optou-se, levando em conta a estrita técnica legislativa, por não repetir disposiçóes do art. $8^{\circ}$ da Lei do Estatuto da Metrópole, particularmente na definição do caráter e das funçóes dos conselhos e da Agem/RM do Vale do Rio Cuiabá, esta sucedida pela SAGPM. De fato, 
o Consem é formado pelos prefeitos de cada um dos municípios integrantes da RM e pelo governador do estado. Porém, dado que o dia a dia da gestão metropolitana exige grande dedicação de tempo e agilidade de decisóes administrativas e técnicas na implementação das FPICs definidas no PDDI, cabe à SAGPM o papel de coordenador e articulador do arranjo institucional criado.

O capítulo II da LCE no 606/2018 previu também:

- que cada município indicasse um servidor público do quadro efetivo para assessorar o prefeito (membro titular do Consem da RM do Vale do Rio Cuiabá) e representá-lo, quando solicitado ou necessário, nos ambientes institucionais da gestão metropolitana;

- a criação de instâncias técnicas colegiadas e grupos de trabalho de caráter técnico-consultivo, formados por representantes de entidades públicas ou privadas, de assessoramento permanente ou transitório ao Codem/RM do Vale do Rio Cuiabá; e

- a criação, no âmbito da Agem da RM do Vale do Rio Cuiabá (com funções atualmente exercidas pela Secretaria Adjunta de Gestão e Planejamento Metropolitano da Sinfra), de gerências ou coordenadorias temáticas ou macrotemáticas, reunindo açóes metropolitanas com forte potencial e sinergia com o propósito de levar adiante a execuçáo dos programas metropolitanos e seus componentes definidos na lei que instituiu o PDDI da RM do Vale do Rio Cuiabá.

\section{A IMPLEMENTAÇÃO DO PLANO METROPOLITANO}

\subsection{Mudança no contexto político-institucional na transição para a implementação do plano}

Um fato importante a registrar é que a lei do PDDI da RM do Vale do Rio Cuiabá foi aprovada nos últimos dias do mandato do governo estadual encerrado em 2018. Como o mesmo grupo político náo se reelegeu para um segundo mandato no período 2019-2022, o novo governo ficou com a incumbência de dar os primeiros passos na implementação do plano metropolitano. Esse cenário previsível de transição chegou a ser objeto de debates em atos públicos realizados durante a elaboração do plano.

Por trás da dificuldade de tornar os planos realidade, costuma estar um imaginário construído sobre a qualidade e os compromissos efetivos da administração pública no país. A nosso ver, a necessidade de planos, por si só, pode refletir fragilidades e descontinuidades no ambiente institucional de gestão. Os planos, portanto, emergiriam como cortes no tempo da gestão pública buscando reinaugurar processos atualizados de ação para o futuro, constituindo apostas renovadas de esperança de mudança e de esgarçamento dos tempos políticos. Por sua vez, em tese, o governo é formado pelos Poderes Executivo e Legislativo, cabendo aos dois trabalhar pela efetivação dos planos que, ao fim, foram formulados no âmbito do Executivo e aprovados no Legislativo. Além disso, sem vincular-se a nenhum dos três poderes do estado, a missão do Ministério Público é fazer cumprir as expectativas de efetivação das leis vigentes no país. Tudo indica que, no caso do MPMT, isso esteja acontecendo.

O trabalho do Ibam junto à extinta Agem da RM do Vale do Rio Cuiabá havia tido como um de seus últimos compromissos a realização de uma atividade de capacitação de pessoal da própria agência, da Secretaria de Estado de Planejamento (Seplan) e de técnicos e gestores dos seis municípios da regiáo (Produto 5b). Essa atividade visou avaliar e planejar os primeiros passos do dia seguinte da conclusão do plano metropolitano. 
Com a aprovação pela ALMT da lei complementar que instituiu o PDDI da RM do Vale do Rio Cuiabá nos últimos dias de mandato da equipe, que deixou o governo estadual em 31 de dezembro de 2018, ficou para a nova equipe - com mandato para o período 2019-2022 - a tarefa de levar adiante a implementaçáo do plano. O ano de 2019 começou tomado por inconsistências na tentativa de localizaçáo institucional da gestão metropolitana no âmbito da estrutura administrativa do governo do estado.

A Agem da RM do Vale do Rio Cuiabá foi extinta no fim de janeiro, passando a competência no assunto para a autarquia, constituída como sociedade de economia mista, MT Participaçóes e Projetos S.A. (MT-PAR), vinculada à Casa Civil. A exemplo do que corresponde essa figura autárquica em outros estados da Federação, como a SC-PAR, por exemplo, a MT-PAR não teria competência para a implementaçâo de um plano multissetorial como o PDDI. Há informaçóes de que o MPMT teria se manifestado contra essa medida administrativa, uma vez que, conforme a lei que instituiu o Estatuto da Metrópole, a natureza da gestão metropolitana exige uma figura jurídica com missão e formato institucional de maior afinidade e capacidade de articulação interna e externa no assunto.

Caberia ainda verificar se foi efetivada a esperada e indispensável incorporação de projetos e açôes previstas no PDDI nas diferentes rubricas do PPA que o governo do estado elaborou para o quadriênio 2020-2023. Na página 46, do Diário Oficial do Estado de Mato Grosso de 27 de dezembro de 2019, que publicou a Lei Estadual n 11.071/2019 dispondo sobre esse PPA, está citada nas referências, sem maiores detalhes bibliográficos, a publicação que consolidou os resultados do processo e das propostas do PDDI (Lopes, 2018). No entanto, em que pese a RM do Vale do Rio Cuiabá e seu entorno formarem a VI Regiáo de Planejamento do Estado de Mato Grosso, como o PPA não é regionalizado, não é possível identificar açôes voltadas clara e exclusivamente para a regiáo. A Ação 5110 prevê recursos para a retomada das obras de implantação do veículo leve sobre trilhos (VLT) entre Cuiabá e Várzea Grande. A Ação 2056 prevê recursos para apoio ao desenvolvimento urbano nos municípios mencionando os planos diretores, mas sem especificar municípios metropolitanos.

\subsection{Primeiras iniciativas de ação no âmbito do PDDI}

Do ponto de vista prático e das ações concretas de implementação de uma agenda metropolitana comprometida com resultados, cabe considerar duas frentes de expectativas: $i$ ) a esperada construção de um bom ambiente de governança compartilhado entre os entes federados ali implicados; e ii) a realização de iniciativas conjuntas concretas, inclusive de investimentos, que pudessem justificar e gerar credibilidade para a gestão metropolitana com base em projetos e ganhos comuns. Pode-se afirmar que, ao longo desse processo, até fevereiro de 2020, nem uma nem outra expectativa foi possível atingir. Parece persistir a ausência de uma cultura de cooperação horizontal entre os municípios, mesmo apoiada em instrumentos como o antigo formato dos consórcios, vertical e interfederativa, entre esferas distintas de governo.

De todo modo, cabe registrar que, motivados ou não pelos debates e resultados decorrentes da elaboraçáo do plano metropolitano no período de meados de 2016 a meados de 2018, ainda no fim do processo de elaboração do plano foram registradas iniciativas de atores da sociedade civil em ações e projetos previstos nos programas e componentes temáticos incluídos no PDDI. Como exemplo disso, em agosto de 2018, já com a proposta do PL do PDDI concluída, tramitando na ALMT e o livro que consolidou o trabalho lançado em 5 de julho de 2019, o Serviço de Apoio às Micro e Pequenas Empresas (Sebrae-MT) lançou 
em parceria com o Conselho de Arquitetura e Urbanismo de Mato Grosso (CAU-MT) e Conselho Regional de Engenharia e Agronomia de Mato Grosso (Crea-MT) o Projeto Casa e Construção, com o objetivo de disseminar e promover a inserção da cultura e de padróes de sustentabilidade na cadeia de valor da construçáo civil, especialmente em escritórios de projetos de arquitetura e engenharia da RM de Cuiabá. Essa iniciativa, na verdade, se inscreve em um dos componentes do Programa Vale Sustentável, incluído no PDDI como resposta à incipiência da adesão do estado ao aproveitamento do sol (abundante na regiáo) como fonte de energia renovável e outros princípios e açóes de sustentabilidade que o ambiente construído pode e deve atender.

O Programa Terra Regular, por sua vez, já tinha uma base sólida de ação liderada por uma comissão da ALMT no tema da resolução de conflitos de limites intermunicipais, que resultou no componente 1 desse programa metropolitano. No âmbito do governo estadual, havia sido lançado também o Programa Terra Legal, voltado para a regularização fundiária urbana e rural e identificado também com outros dois componentes do Programa Terra Regular.

No dia 12 de setembro de 2019, o coordenador técnico do PDDI pelo Ibam fez uma apresentaçáo, em Cuiabá, para a nova equipe da Sinfra, sobre o processo, os resultados e, particularmente, o conteúdo programático do PDDI da RMdo Vale do Rio Cuiabá, tal como instituído na LCE no 609/2018. Essa atividade, realizada a convite da Sinfra e custeada pelo próprio Ibam, visou atualizar e debater com a nova equipe da secretaria o conteúdo, as oportunidades e as açóes imediatas demandadas pela regiáo para a implementação progressiva do plano metropolitano.

Entre outras recomendaçóes e, como exemplo, considerando o franco processo de conurbaçáo verificado entre as cidades de Cuiabá e Santo Antônio de Leverger, foi sugerido à nova equipe da Sinfra, responsável pela gestáo metropolitana, que se priorize a elaboração de um projeto estruturante e multissetorial para o eixo estrutural da rodovia MT-040, que liga as duas cidades, conforme proposto na lei do PDDI. Na ocasião desse encontro, foi lembrada também a necessidade de se cumprir o prazo de seis meses (desde entáo já esgotado) para que o órgão gestor metropolitano tomasse medidas definidas no capítulo das disposiçóes finais e transitórias da lei.

ASAGPM/Sinfra criou uma página na internet de acesso à base de informaçóes sobre o planejamento e a gestão metropolitana do governo do estado de Mato Grosso. ${ }^{2}$ Esta secretaria vem também procurando associar suas açóes aos programas metropolitanos e a seus respectivos componentes criados no PDDI. Porém, em que pese a importância dessas ações para o desenvolvimento metropolitano, o que registramos a seguir são algumas iniciativas do governo estadual que não caracterizam necessariamente açôes de caráter interfederativo envolvendo cooperação com municípios metropolitanos.

Em documento elaborado pela SAGPM/Sinfra (Gonçalves, 2019), estão registradas algumas dessas iniciativas que apontam para o previsto no PDDI. Entre as prioridades, estão a elaboração dos planos metropolitanos de mobilidade, saneamento básico e gestáo integrada de resíduos sólidos, todos previstos no art. 85 da lei do PDDI e alguns já em processo licitatório. No caso da mobilidade, cabe registrar que a prefeitura de Cuiabá também abriu processo licitatório para elaboração do seu plano municipal com referências e exigências na escala metropolitana. Como esses dois planos tendem a ser elaborados concomitantemente, espera-se que o Codem/RM do Vale do Rio Cuiabá seja o fórum de diálogo para a coordenação eficaz desses dois importantes 
instrumentos de planejamento. No caso do saneamento básico, na época da elaboração do PDDI, foram criados planos para 106municípios do estado de Mato Grosso, incluindo os quatro com menor população da RM do Vale do Rio Cuiabá: Acorizal, Chapada dos Guimarães, Nossa Senhora do Livramento e Santo Antônio de Leverger. Esses planos estruturados pela Universidade Federal de Mato Grosso (UFMT), com o apoio da Fundação Nacional de Saúde (Funasa), deverão ser compatibilizados com o anunciado plano metropolitano.

No âmbito do Programa Gestão Metropolitana do PDDI (componente gestão da informação), está previsto o desenvolvimento, com o apoio do Instituto de Terras de Mato Grosso (Intermat), da base cartográfica do planejamento da RM do Vale do Rio Cuiabá. A prioridade é gerar informação atualizada e acessível a todos em cartas geotécnicas e de aptidão à urbanização, além de apoiar a atualização da legislação e a gestão urbanística em geral nos municípios. O Codem/RM do Vale do Rio Cuiabá teve sua composição renovada para um novo mandato de seus membros.

O Programa Economia Regional Dinamizadora, em seus três componentes, enquadra alguns outros projetos do governo estadual. Um projeto de agroecologia prevê a incorporação inicial de cinquenta famílias do distrito de Baús no município de Acorizal à produção cooperativista, inclusiva, sustentável e circular. Pelas suas características, este projeto se identifica também com o Programa Vale Sustentável. Ainda associado e em apoio ao Programa Economia Regional Dinamizadora o próprio titular em exercício na SAGPM desenvolveu o índice de crescimento sustentável nos municípios (ICSM) para todo o estado e, portanto, também aplicável aos municípios da RM do Vale do Rio Cuiabá. O ICSM se identifica também com o componente de gestão da informação do Programa Gestão Metropolitana. A aplicação experimental deste índice aos municípios metropolitanos mostra um potencial de avaliaçáo do desenvolvimento regional por uma série de critérios. A SAGPM juntamente com a Prefeitura de Santo Antônio de Leverger também articula a implantação no município de um campus avançado da Universidade Federal da Integração Latino-Americana (Unila) para a realização de cursos de extensão em assuntos de interesse da região.

No momento, algumas outras açóes do governo estadual podem ser identificadas com o Programa Cidadania para o Desenvolvimento do PDDI. Entre elas está a criação da moeda Pacu, de incentivo ao empreendedorismo de mulheres em situação de vulnerabilidade social.

Uma questão talvez polêmica, dado o contexto geográfico e institucional da RM do Vale do Rio Cuiabá, diz respeito à anunciada incorporação de novos municípios ao ambiente de gestáo interfederativa da região, provavelmente do entorno metropolitano. $\mathrm{O}$ art. $2^{\circ}$, parágrafo 3ํ da LCE nº 609/2018 dispóe sobre critérios e mecanismos mínimos para tal, cabendo ao Codem/RM do Vale do Rio Cuiabá deliberar sobre o assunto.

\section{CONSIDERAÇÕES FINAIS}

Este registro foi possível realizar tendo em vista a conclusão e aprovação relativamente recente do plano metropolitano examinado. Um aprofundamento das análises e apontamentos feitos neste estudo seria possível com um trabalho mais capilar e expedito junto aos atores locais da regiáo.

Conforme sugerido antes, se a transiçâo de governo verificada de 2018 para 2019 provocou descontinuidade nas expectativas geradas pelo advento do PDDI, o processo de elaboração do plano metropolitano pode ter operado alguma mudança pedagógica na compreensáo de alguns agentes públicos e da sociedade civil sobre esse instrumento de planejamento e ação interfedera- 
tiva. Isso pode ter criado um campo mínimo de atenção à agenda da regiáo. Quanto aos municípios, até o momento há alguns registros de internalização sistemática na esfera local da agenda metropolitana consolidada no PDDI, mas restritos aos planos diretores, conforme mencionado na seção anterior. Só uma pesquisa mais sistemática seria capaz de descrever com mais riqueza de dados o "dia seguinte" da aprovação do PDDI na regiáo, considerando os diversos atores e ambientes de expectativas em relação ao plano metropolitano.

$\mathrm{Na}$ transição de governo, também operada na esfera federal em 2018-2019, o cenário da economia do país associado à crise financeira dos estados, particularmente o de Mato Grosso, gerou uma sensação de estagnação econômica e de inércia para as iniciativas de governo. Três dos seis municípios da RM do Vale do Rio Cuiabá acabaram também por se declarar em estado de calamidade financeira.

Cabe reconhecer, no entanto, que o mesmo papel desempenhado pelo MPMT na iniciativa de pautar o tema metropolitano junto ao governo do estado de Mato Grosso para a elaboração do PDDI em 2016, por força do Estatuto da Metrópole, aprovado em janeiro de 2015, parece agora constitui-lo em protagonista para a implementação do plano metropolitano em busca de respeito à lei e de eficácia da açáo de governo na regiáo. Por sua vez, o papel e as competências do estado federado parecem sugerir outras possibilidades para a sua participação no planejamento regional e nas açóes de desenvolvimento no país.

Em outubro de 2020, haverá eleiçôes municipais, o que significa que a partir de janeiro de 2021 interlocutores locais que não participaram do processo de construção do plano metropolitano poderão assumir os cargos nas novas administraçôes. $\mathrm{Na}$ hipótese de que as equipes de governo dos seis municípios metropolitanos sejam trocadas, estaremos diante de um cenário de poucos interlocutores na gestão interfederativa metropolitana que tenham participado do processo de elaboração do PDDI da RM do Vale do Rio Cuiabá. Saem os governos transitórios, permanecem as administraçóes com seus servidores públicos.

Finalmente, e tomando como caso esse rico processo no Vale do Rio Cuiabá, verifica-se que o âmbito da gestáo metropolitana pode emergir como um laboratório privilegiado de experimentação sobre possibilidades e limites da governação interfederativa no Brasil e quem sabe mesmo sobre o desenho da própria Federação brasileira.

\section{REFERÊNCIAS}

BRASIL. Lei Federal no 13.089, de 12 de janeiro de 2015. Institui o Estatuto da Metrópole, altera a Lei $\mathrm{n}^{\mathrm{o}}$ 10.257, de 10 de julho de 2001, e dá outras providências. Diário Oficial, Brasília, 13 jan. 2015.

ESTADO DE MATO GROSSO. Lei Complementar no 609, de 27 de dezembro de 2018. Institui o Plano Diretor de Desenvolvimento Integrado da Região Metropolitana do Vale do Rio Cuiabá - PDDI/RMVRC, e dá outras providências. Diário Oficial do Estado de Mato Grosso, Cuiabá, 2018.

. Lei no 11.071, de 27 de dezembro de 2019. Dispóe sobre o Plano Plurianual para o quadriênio 2020-2023. Diário Oficial do Estado de Mato Grosso, Cuiabá, 2019.

GONÇALVES, F. O. S. O Plano de Desenvolvimento Integrado da Regiáo Metropolitana do Vale do Rio Cuiabá e a reestruturaçáo da regiáo metropolitana. Cuiabá: SAGPM; Sinfra/MT, 2019.

LOPES, A. C. Plano Diretor de Desenvolvimento Integrado da Regiáo Metropolitana do Vale do Rio Cuiabá. Rio de Janeiro: Ibam; Cuiabá: Agem/VRC, 2018. 192 p. 


\section{ANEXO A}

\section{QUADRO A.1}

\section{Evolução da legislação estadual em assuntos metropolitanos}

\begin{tabular}{|c|c|}
\hline Lei Complementar Estadual (LCE) № 028, de 1993. & Cria o aglomerado urbano de Cuiabá e Várzea Grande. \\
\hline LCE no 83, de 18 de maio de 2001. & Dispõe sobre o aglomerado urbano de Cuiabá e Várzea Grande. \\
\hline LCE no 249, de 26 de julho de 2006. & Altera e acrescenta dispositivo à LCE no 83/2001. \\
\hline LCE no 340, de 17 de dezembro de 2008. & $\begin{array}{l}\text { Dispõe sobre a instituição e a gestão de regiões metropolitanas (RMs) no } \\
\text { Estado de Mato Grosso. }\end{array}$ \\
\hline LCE no 359, de 27 de maio de 2009. & $\begin{array}{l}\text { Cria a RM do Vale do Rio Cuiabá, composta por Cuiabá, Nossa Senhora do } \\
\text { Livramento, Santo Antônio de Leverger e Várzea Grande. }\end{array}$ \\
\hline LCE no 499, de 22 de julho de 2013. & $\begin{array}{l}\text { Dispõe sobre o sistema de gestão da RM do Vale do Rio Cuiabá. São criados: } \\
\text { Conselho Deliberativo Metropolitano (Codem), Agência de Desenvolvimento } \\
\text { Metropolitano (Agem) e Fundo de Desenvolvimento Metropolitano (FDM). }\end{array}$ \\
\hline Lei Complementar no 577, de 19 de maio de 2016. & $\begin{array}{l}\text { Altera a LC no 359/2009, incluindo na RM Vale do Rio Cuiabá os municípios } \\
\text { de Acorizal e Chapada dos Guimarães. }\end{array}$ \\
\hline \multicolumn{2}{|l|}{ LCE no 609, de 27 de dezembro de 2018.} \\
\hline LCE no 612 , de 28 de janeiro de 2019. & Dispõe da organização administrativa do Poder Executivo estadual. \\
\hline Decreto Estadual n 51, de 8 de março de 2019. & $\begin{array}{l}\text { Foi encontrada referência a este decreto no histórico do assunto, mas não foi } \\
\text { possível acessar o texto legal. }\end{array}$ \\
\hline Decreto Estadual no 112, de 17 de maio de 2019. & $\begin{array}{l}\text { Dispõe sobre a gestão dos bens, direitos, obrigações e das atividades da } \\
\text { extinta Agem da RM do Vale do Rio Cuiabá pela Secretaria de Estado de Pla- } \\
\text { nejamento e Gestão (Seplag) para fins de regularização contábil, patrimonial } \\
\text { e de pessoal. }{ }^{1}\end{array}$ \\
\hline Decreto Estadual no 145, de 19 de junho de 2019. & $\begin{array}{l}\text { Art. 18: estabelece que "as atividades administrativas executadas pela } \\
\text { autarquia extinta Agem da RM do Vale do Rio Cuiabá serão absorvidas pela } \\
\text { Seplag", conforme parecer da Procuradoria-Geral do Estado (PGE) no 221/ } \\
\text { SGACI/2019 e Decreto n } 112 \text {, de } 17 \text { de maio de } 2019 \text {. }\end{array}$ \\
\hline Decreto Estadual n 201, de 16 de agosto de 2019. & $\begin{array}{l}\text { No art. 3o, prevê na estrutura da Secretaria de Estado de Infraestrutura e } \\
\text { Logística (Sinfra) o cargo de nível de direção superior de secretário adjunto de } \\
\text { gestão e planejamento metropolitano. }\end{array}$ \\
\hline Lei Complementar no 633, de 14 de outubro de 2019. & $\begin{array}{l}\text { Atribui à Sinfra as atividades antes exercidas pela agora extinta Agem da RM } \\
\text { do Vale do Rio Cuiabá. }\end{array}$ \\
\hline $\begin{array}{l}\text { Diário Oficial do Estado de Mato Grosso, de } 23 \text { de agosto de } 2019 . \\
\text { Ato no } 3.800 / 2019 .\end{array}$ & Cria, no âmbito da Sinfra, a SAGPMe nomeia seu titular para o cargo de direção. \\
\hline
\end{tabular}

Elaboração do autor.

Nota: ${ }^{1}$ Esse decreto se apoia no Parecer no 221/SGACI/2019 da PGE e foi editado em função da figura jurídica e da missão da autarquia (sociedade de economia mista) MT Participações e Projetos S.A. (MT-PAR), vinculada à Casa Civil e antes equivocadamente instituída como sucessora das atividades da Agem/RM do Vale do Rio Cuiabá, não estar habilitada ao cumprimento do estabelecido para a gestão metropolitana na lei federal que instituiu o Estatuto da Metrópole. 

Ipea - Instituto de Pesquisa Econômica Aplicada

EDITORIAL

\section{Coordenação}

Reginaldo da Silva Domingos

Assistente de Coordenação

Rafael Augusto Ferreira Cardoso

\section{Supervisão}

Camilla de Miranda Mariath Gomes

Everson da Silva Moura

\section{Editoração}

Aeromilson Trajano de Mesquita

Cristiano Ferreira de Araújo

Danilo Leite de Macedo Tavares

Herllyson da Silva Souza

Jeovah Herculano Szervinsk Junior

Leonardo Hideki Higa

\section{Capa}

Danielle de Oliveira Ayres

Flaviane Dias de Sant'ana

Projeto Gráfico

Renato Rodrigues Bueno

The manuscripts in languages other than Portuguese published herein have not been proofread.

\section{Livraria Ipea}

SBS - Quadra 1 - Bloco J - Ed. BNDES, Térreo

70076-900 - Brasília - DF

Tel.: (61) 2026-5336

Correio eletrônico: livraria@ipea.gov.br 

Composto em adobe garamond pro 11,5/13,8 (texto)

Frutiger 67 bold condensed (títulos, gráficos e tabelas) Brasília-DF 



\section{Missão do Ipea}

Aprimorar as políticas públicas essenciais ao desenvolvimento brasileiro por meio da produção e disseminação de conhecimentos e da assessoria ao Estado nas suas decisões estratégicas. 